\title{
Alteridades sociales de la migración internacional de retorno a Zacatecas
}

\author{
Miguel Moctezuma
}

Este ensayo se refiere a la presencia de un cambio en el patrón de migración de retorno, destacando que el retorno de Estados Unidos a México ha crecido y viene acompañado de la presencia de un numeroso grupo de menores que nacieron en Estados Unidos. Este aspecto, sumado al freno de la migración, termina por impactar en los resultados del crecimiento de la población, aunque en Zacatecas aún se encuentra un despoblamiento acumulado.

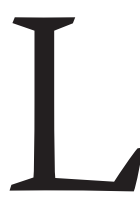

as causas de la migración de trabajadores entre dos países están en el origen y el destino. Lo que en un país es «expulsión» de migrantes y despoblamiento, en otro se manifiesta como «atracción»y formación de comunidades filiales de inmigrantes. Cuando la investigación se encamina hacia la formulación simplista de que las «causas» de la migración están en el origen, el concepto de análisis que se utiliza es el de expulsión poblacional. Por el contrario, si se postula que las causas de la migración están en el destino, la migración es vista preponderantemente como atracción. Pero expulsión y atracción son dos fases de un solo proceso, e incluso son dos fases incompletas, ya que ignoran la dialéctica de que las causas de la génesis de la migración con el tiempo se transforman en consecuencias y éstas nuevamente en causas.

Asimismo, cuando a esta crítica le sumamos la complejización que deriva de la perspectiva transnacio- 


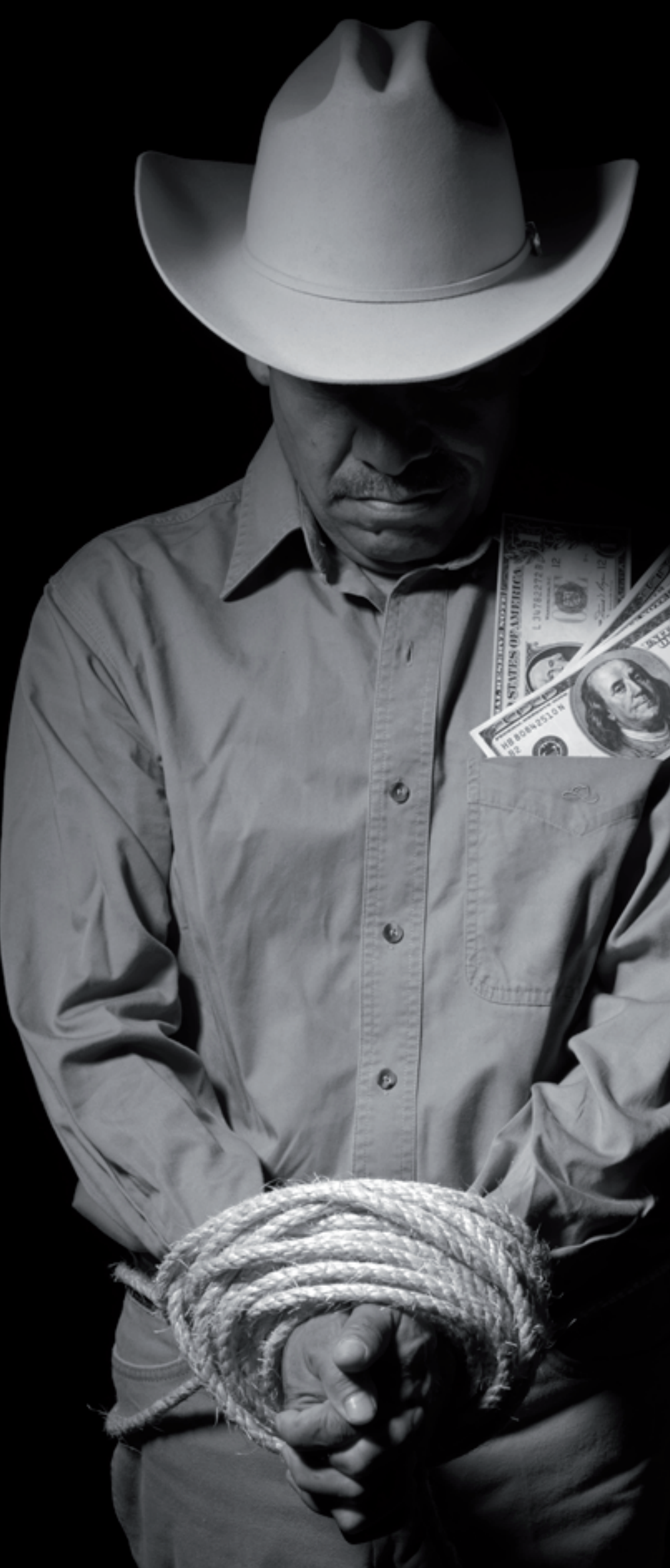

nalista, resulta obvio que la simplificación del modelo de la expulsión-atracción poblacional está orientado por el nacionalismo metodológico. Peor aún, se pierde de vista la tesis de que la migración entre dos países produce, más allá de sus confines territoriales, relaciones sociales de simultaneidad entre ambos. ${ }^{1}$

Hoy en día estamos ante un retorno de migrantes que abarca repatriaciones, retornos voluntarios individuales y retornos de tipo familiar; éstos últimos, al igual que la drástica reducción de la emigración, son las dos alteridades que constituyen la principal característica de la migración México-Estados Unidos. Por tanto, es un error suponer que los migrantes regresan al país porque se abrieron nuevas oportunidades para la movilidad social, como se dice respecto de los que ahora no emigran, ${ }^{2}$ cuya verdadera explicación se encuentra en la crisis económica de Estados Unidos.

Según Olivier Blanchard, economista del Fondo Monetario Internacional (FMI), la crisis financiera iniciada en 2008 necesitará de unos 10 años (2018) para recuperarse. ${ }^{3}$ Esta opinión "conservadora» indica que estamos ante un retorno de familias de migrantes que ha dejado de ser coyuntural; por tanto, tenemos que prever sus implicaciones sociales en México. Y esto mismo es válido para el freno a la emigración.

\section{DINÁMICA DE LA POBLACIÓN MEXICANA}

Empecemos por señalar que el Consejo $\mathrm{Na}$ cional de Población (Conapo) proyectó para 2010 una población en México de 108.4 millones de habitantes. ${ }^{4}$ Esta proyección fue superada en casi cuatro millones (112’336,538). Parte de ese crecimiento se debió al freno que presentó la migración internacional, sumada al retorno de migrantes con su descendencia.

Considerando la dinámica de población de 20002005, las entidades que presentaron el más bajo crecimiento en su dinámica poblacional fueron Michoacán $(-0.1 \%)$, Zacatecas (0.2\%), Guerrero (0.2\%), Distrito Federal (0.2) y Sinaloa (0.5\%); en cambio, entre 2005-2010, sólo el Distrito Federal mantuvo un crecimiento bajo, equivalente a $0.3 \% .{ }^{5}$ Por supuesto, ésta es una tendencia nacional que entre 2005-2010 se manifiesta globalmen- 
te en una tasa anual de crecimiento promedio de la dinámica poblacional de $1.8 \%$, superior en $0.8 \%$ respecto a la experimentada en 2005, lo que resulta paradójico, ya que desde 1960 en cada censo de población se había mantenido una tendencia poblacional descendente.

Ahora bien, el crecimiento no previsto para 2010 obedece al freno que experimenta la migración, al retorno de los migrantes y al crecimiento de la inmigración, en este caso de los descendientes de migrantes que ingresan por primera vez con sus padres a México y que a pesar de ser binacionales fueron registrados como «extranjeros».

$\mathrm{Si}$ en un ejercicio metodológico comparamos la población de 2010 con la que en 2005 le correspondía, se observan tres excedentes importantes: el primero de 726,476 en los grupos de edad entre 30-34 y 35-39 años; el segundo, por 1'289,493 en los grupos de 5-9 y 10-14 años, y el tercero, de 342,079 en el grupo de 0-4 años; además de otros excedentes menores: 73,989 y 49,036 entre $15-19$ y $50-54$ años, respectivamente. En conjunto, todos esos excedentes suman 2'481,073 habitantes. ${ }^{6}$

La explicación del crecimiento poblacional está en identificar la alteridad: los migrantes están retornando a México junto con su descendencia; esto resalta en los grupos de edades con excedentes. Así, los retornos de migrantes en 30-34 y 35-39 años deben más o menos corresponder con la inmigración a México de menores comprendidos entre 0-4, 5-9 y 10-14 años.

El Censo de población y vivienda de 2010 registra un millón 310 mil menores de 15 años de edad que entre 2005 y 2010 ingresaron a México. De todos ellos, 960 mil nacieron en el extranjero y 350 mil son menores de retorno de las mismas edades. La población correspondiente al grupo de edades comprendido entre $0-4$ años se incrementó como resultado del retorno de parejas de migrantes en edad reproductiva, cuya concepción ocurrió en Estados Unidos y los nacimientos se produjeron en México; o bien, ambos aspectos sucedieron en México.

\section{FLUjos DE LA}

\section{MIGRACIÓN INTERNACIONAL}

En lo relativo a la magnitud que actualmente alcanza la migración internacional, es conveniente distinguir entre mexicanos nativos que realmente emigraron respecto de los descendientes de mexicanos que nacieron fuera de México y no emigraron. Desde hace tres décadas los mexicanos representan cerca de un tercio de toda la población inmigrante radicada en el vecino país del norte. ${ }^{7}$ Para 2010, con base en la encuesta continua de población (CPS, por sus siglas en inglés), se estima que la población de origen mexicano es cercana a los 33 millones de habitantes, de los cuales 11.9 nacieron en México y 21.5 millones son descendientes de mexicanos. En conjunto representan $29.7 \%$ de la población residente en México.

Por otro lado, sin considerar la migración circular que se desplaza en ambos sentidos, para 2005 se calculó que había 10.6 millones de nativos mexicanos residiendo en Estados Unidos (de un total de 27.7 millones de población de origen mexicano). Entre 2000 y 2005, emigraron y se establecieron en Estados Unidos un promedio de 492 mil mexicanos por año. ${ }^{8}$ Entre 2005 y 2010, la emigración mexicana que emigró anualmente y se estableció en ese país se redujo a 222,455 migrantes. ${ }^{9}$ Eso significa que en todo el quinquenio hubo una caída drástica de la migración establecida de origen mexicano de hasta 44.5\%. La reducción es más elocuente si consideramos que este promedio a partir de 2007 ha venido descendiendo año con año. El Pew Center Hispanic estima que para 2010 menos de 100 mil mexicanos tuvieron éxito al cruzar la frontera hacia Estados Unidos.

Junto con la reducción de la emigración y el establecimiento de los migrantes mexicanos en Estados Unidos, crece la migración de retorno. Entre 1995-2000 retornaron a México 267,150 personas y entre 20052010 la cantidad se elevó a 350,719. La disminución de la emigración y el crecimiento del retorno se van a mantener constantes mientras no se recupere plenamente la economía estadounidense.

Hasta aquí, orientados por la perspectiva transnacional que postula el principio de la simultaneidad, podemos decir que en México el freno a la emigración se asocia con una drástica reducción en la demanda de fuerza de trabajo en Estados Unidos; asimismo, el retorno de migrantes se transforma en excedente de población. Si antes se ponía el acento en el destino y se insistía en el mantenimiento de lazos de los migrantes con sus familias, hoy tenemos que subrayar la alteraciones familiares en México como resultado del retorno de los migrantes y sus descendientes, es decir, al mismo fenómeno, en la medida que consencias $y$ éstas nuevamente en causas. constituye una misma unidad impacta a ambos países y se transforma en su contrario. 
MigRACIÓN INTERNACIONAL DE ZACATECAS

Con base en la CPS $^{10}$ y la información de Conapo, se estima que para 2010 existen aproximadamente 572 mil zacatecanos residiendo en Estados Unidos. Entre 2005 y 2010, el número de migrantes establecidos en Estados Unidos que nacieron en Zacatecas creció en 63 mil personas, esto significa que en promedio cada año se establecieron 13 mil zacatecanos. Esta cifra resulta reducida si comparamos la pérdida anual de la entidad estimada por Conapo entre 2000 y 2005, la cual fue del orden de 16 mil.

Para 2005, los migrantes zacatecanos establecidos en Estados Unidos representaban 36\% de la población residente en la entidad ${ }^{11}$ y para 2010 este sector de la población constituye $38.4 \%$. Por la proporción de la migración residente, ningun otro estado supera a Zacatecas. Este porcentaje, sumado a la recepción de remesas, migración circular y migración de retorno, coloca a Zacatecas en el índice de intensidad migratoria más alto del país, tanto en 2000 como en $2010 .^{12}$

A pesar de que en los años recientes la emigración se ha reducido drásticamente, la información nacional derivada del Censo de población y vivienda de 2010 da cuenta de una emigración entre 2005 y 2010 de 10 personas por cada mil habitantes, mientras que Zacatecas presenta una emigración de 21.3 por cada mil personas. No está por demás subrayar que la sequía de 2011, a pesar de ser la más severa de los últimos 70 años, no se tradujo en un crecimiento de la emigración internacional, sobre todo porque como la migración es de tipo laboral, es necesario considerar la oferta y la demanda del país receptor.

\section{LA POBLACIÓN DE ZACATECAS}

La dinámica de la población de Zacatecas transita actualmente por dos procesos contradictorios: por un lado, entre 2005 y 2010 se produce un proceso de recuperación poblacional expresado a simple vista como «crecimiento» de la población similar a la tendencia nacional y, por otro, a partir de 1990 aún persiste, como corolario de los efectos que ha tenido la emigración, un despoblamiento acumulado. Zacatecas observa como tendencia un crecimiento promedio anual, entre 20052010, de 1.7\%, mientras que el país presenta un crecimiento de 1.8\%; sin embargo, cinco años antes Zacatecas tenía un crecimiento cinco veces más lento que la dinámica nacional. Así, mientras que entre 2000 y 2005 la entidad tendió hacia un crecimiento cercano a cero (14,082 habitantes), entre 2005 y 2010 la entidad aumentó su población 8.7 veces (122,976 personas).

El crecimiento «explosivo» del número de habitantes de 2010 se explica por el freno que ha experimentado la emigración y por el retorno a Zacatecas de un flujo de población que años antes había emigrado a Estados Unidos y que regresa con todo y sus hijos. Los municipios que, según Conapo, se vieron mayormente impactados por el retorno de migrantes fueron Francisco R. Munguía, Susticacán, Chalchihuites, Valparaíso, Villa González Ortega, Río Grande y Nochistlán. ${ }^{13}$

Sin considerar el impacto poblacional que presenta el freno a la emigración, los datos del impacto que tienen los migrantes de retorno en el crecimiento de la población en 2010 y en comparación al mismo grupo de 2005 son los siguientes: a) se observa una población extra equivalente a 10,163 habitantes en el grupo de 30-39 años; b) resalta un segundo excedente de 11,291 habitantes en el grupo que abarca 5-14 años, y c) de manera similar, en el grupo de 0-4 años se registra una población superior de $8207 .^{14}$

Contrariamente, se aprecia un pequeño déficit de población localizado, esencialmente, entre las edades de 15-19 y 20-24 años, extendiéndose para las mujeres hasta los 25-29 años, es decir, con la crisis la migración se hizo todavía más selectiva.

\section{ÍNDICE DE}

INTENSIDAD MIGRATORIA

La construcción del índice de intensidad migratorio es el resultado de la combinación de cuatro variables: las viviendas que reciben remesas, los migrantes que residen en Estados Unidos, los migrantes circulares y los migrantes que retornan.

Un aspecto que llama la atención es la existencia de viviendas receptoras de remesas que en algunos municipios alcanzan más de 30\%, como Susticacán y Francisco R. Munguía. Existen otras viviendas que se ubican 


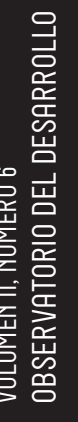

entre 25 y $30 \%$ de hogares receptores de remesas, como Huanusco, Moyahua, Juchipila, Apozol, Nochistlán, Apulco, Tepechitlán y Momax. Esto lleva a subrayar que, considerando al hogar receptor de remesas, sus ingresos, al tiempo que ayudan a resolver sus necesidades en el origen, muestran una dependencia extrema respecto del destino.

El índice de intensidad migratoria fue elaborado por Conapo en 2000. En ese entonces, la migración de retorno no incluía a los menores binacionales que actualmente arriban a México acompañando a sus padres. En el Censo de población y vivienda de 2010, éstos fueron registrados a partir del criterio legal de inmigrantes. En efecto, son parte del flujo migratorio, sólo que son su resultado. Pero en la medida en que forman parte de la migración, estos debieran de ser considerados como una nueva variable que debe ser integrada al índice de intensidad migratoria.

\section{EL PROCESO}

\section{DE DESPOBLAMIENTO}

Así, a diferencia del pasado reciente, en 2010, comparándolo con 2005, se registran solamente seis municipios con despoblamiento: Atolinga, El Plateado, Jiménez del Teul, Momax, Moyahua y El Salvador. ${ }^{15}$ Sin embargo, ése es un análisis de tiempo corto que oculta el proceso

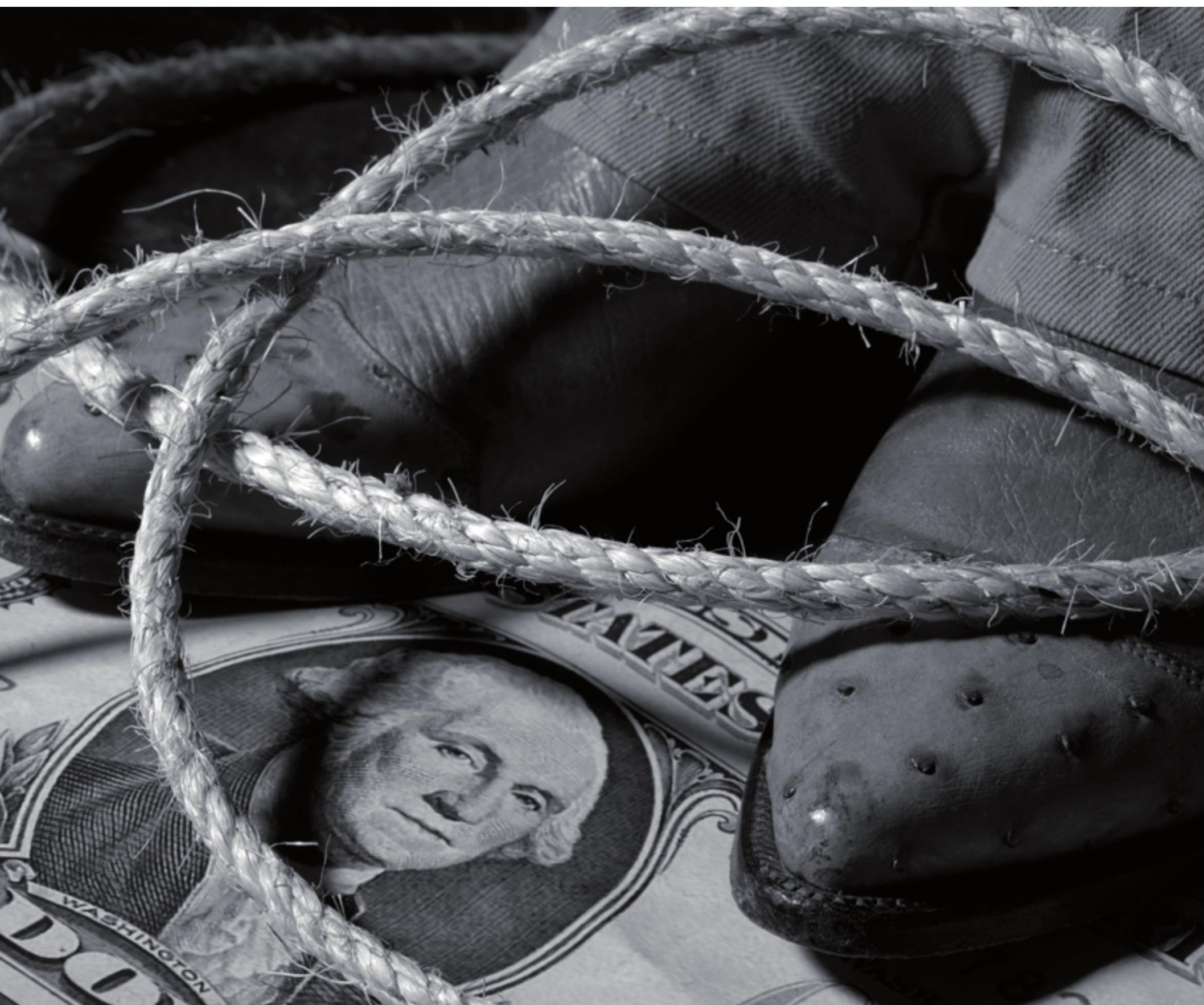


entero. En efecto, en 2010, de los 58 municipios que contempla la entidad zacatecana, 30 de ellos aún presentan una población menor a la de hace 20 años (53.8\%), 28 respecto de la población de 15 años atrás (50\%) y 25 en relación a la población de 10 años antes (43.9\%). Entonces, lo que en 2010 se presenta es un despoblamiento acumulado. ${ }^{16}$

Con relación al proceso del despoblamiento acumulado que experimenta Zacatecas se observa complementariamente un fenómeno típico que afecta de manera dramática a los grupos de edades que se ven mayormente impactados por la emigración internacional. Para 2005, en el grupo de edades de 25-29 años, Apulco tenía sólo 49 varones por cada 100 mujeres; Susticacán, 53; Concepción del Oro, 56; Nochistlán y Valparaíso, 59; es decir, en estos municipios existía un déficit de varones que indicaba que la reproducción de la población se había convertido en un problema para la sustentabilidad social y reproductiva. En 2010, con el retorno de migrantes, aún aparecen en una situación difícil los municipios de Apulco, Tabasco, Mezquital del Oro, Nochistlán y Valparaíso. Ese escenario mejoró un poco, pero sigue siendo problemático.

\section{Conclusiones}

Mientras que hasta 2005 experimentó un fase sostenida de despoblamiento, de 2005 a 2010 Zacatecas observa un proceso de recuperación poblacional. Aún así, desde 1990 se vive una despoblamiento acumulado. Aquí la alteridad indica que la recuperación poblacional se da por la vía de la migración de retorno, pero a diferencia del pasado inmediato, en este caso se trata de retorno de tipo familiar, que termina alterando la vida entera de la estructura y dinámica de los hogares a donde arriban.

En Zacatecas existen municipios población de Zacatecas transita por dos procesos contradictorios: por un lado, se produce un proceso de recuperación poblacional expresado como un «crecimiento»,

$y$, por otro, persiste un despoblamiento acumulado.

\section{Referencias}

1 Rouse Roger, «Mexican migration and the social space of postmodernism», Diaspora: a Journal of Transnational Studies, volumen 1, número 1, 1991.

2 Margarita Vega, «Cae migración a EU, dice Segob», Reforma, 12 de julio de 2011.

3 «logs.cincodias.com/punto-basico/2012/10/la-crisis-durará-10-añoshtml.

4 〈http://www.somede.org/documentos/boletin/Boletin_sOMEDE_No_1.pdf).

5 INEGI, Censo de población y vivienda, 2000 y 2010, II Conteo de población 2005.

6 INEGI, II Conteo de población 2005 y Censo de población y vivienda, 2010.

7 Selene Gaspar Olvera y Rafael López Vega, «El comportamiento regional de la inserción laboral de los mexicanos en Estados Unidos», Migración y Desarrollo, número 13, 2009.
8 Conapo con base en Bureau of Census, Current Population Survey (CPS), marzo de 1994-2007, p. 70.

9 INEGI, Censo de población y vivienda, 2010.

10 Estimaciones del Bureau of Census, Current Population Survey (CPS), marzo de 1994-2007.

11 Conapo, Proyecciones de la Población 2000-2050.

12 Conapo, Índice de Intensidad Migratoria, México-Estados Unidos 2000, 2002; Conapo, Indice de Intensidad Migratoria, México-Estados Unidos 2010, 2012, en 〈http://www.conapo. gob.mx/work/models/CONAPO/intensidad_migratoria/anexos/Anexo_B2.pdf〉.

13 Idem.

14 Inegi, II Conteo de Población 2005; INEGI, Censo General de Población 2010.

15 Idem.

16 Idem; Censo General de Población y Vivienda 2000. 